
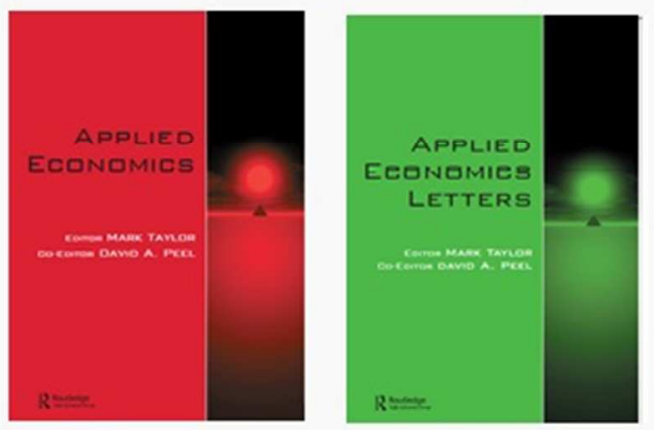

\title{
Growth convergence and local steady states across Chinese prefectures
}

\begin{tabular}{|r|l|}
\hline Journal: & Applied Economics \\
\hline Manuscript ID & AEL-2016-0212.R1 \\
\hline Journal Selection: & $\begin{array}{l}\text { Applied Economics Letters incorporating Applied Financial Economics } \\
\text { Letters }\end{array}$ \\
\hline Date Submitted by the Author: & $08-J u n-2016$ \\
\hline Complete List of Authors: & $\begin{array}{l}\text { Frattini, Federico; University of Ferrara, Department of Economics and } \\
\text { Management } \\
\text { Nicolli, Francesco; National Research Council, Research Institute on } \\
\text { Sustainable Economic Growth; University of Ferrara, Department of } \\
\text { Economics and Management } \\
\text { Prodi , Giorgio; University Ferrara, Department of Economics and } \\
\text { Management }\end{array}$ \\
\hline JEL Code: & $\begin{array}{l}\text { O49 - Other < O4 - Economic Growth and Aggregate Productivity < O - } \\
\text { including Middle East < O5 - Economywide Country Studies < O - Economic } \\
\text { Development, Technological Change, and Growth }\end{array}$ \\
\hline Keywords: & \begin{tabular}{l} 
China, convergence, foreign direct investments, patents \\
\hline
\end{tabular} \\
\hline
\end{tabular}




\title{
Growth convergence and local steady states across Chinese prefectures
}

\author{
F. Frattini, F. Nicolli and G. Prodi
}

Federico Frattini (corresponding author)

University of Ferrara, Department of Economics and Management

Via Voltapaletto 11, Ferrara FE Italy

E-mail: federico.frattini@unife.it

Francesco Nicolli

National Research Council, Research Institute on Sustainable Economic Growth

Via Bassini 22, Milan MI Italy

University of Ferrara, Department of Economics and Management

Via Voltapaletto 11, Ferrara FE Italy

E-mail: francesco.nicolli@unife.it

Giorgio Prodi

University of Ferrara, Department of Economics and Management

Via Voltapaletto 11, Ferrara FE Italy

E-mail: giorgio.prodi@unife.it

\begin{abstract}
This paper investigates how economic growth paths diverge across Chinese prefectural cities. Based on the conditional convergence hypothesis, the analysis includes inward foreign direct investments and patent applications to the European Patent Office as additional proxies of steady-state income levels and allows the convergence parameter to vary across groups. The results show that within-convergence rates are different across groups, but growth drivers positively affect both intraregional and interregional catching up.
\end{abstract}

Keywords: China; convergence; foreign direct investments; patents

Subject classification codes: O49; O53 


\section{Introduction}

An impressive long-term growth process has produced sizable regional income disparities in China. Economic growth increased in the Coastal area first, fostered by a strategy of regulated opening and transition (Naughton 2007). Since the late-80s, Inward Foreign Direct Investments (IFDI) have made it possible to import physical capital and technologies, as well as develop indigenous technological capabilities (Fu 2008). Innovation activities actually began rising the next decade, mostly clustering around initial locations (Fan 2014).

A consolidated strand of literature has found a significant positive relationship between IFDI and economic growth in China, whose intensity positively depends on human capital and negatively on technological gaps (Li and Liu 2005). Following on from this evidence but using an alternative approach to usual simultaneous-equation modelling, this letter investigates how IFDI and Knowledge Stocks (KS) generated by indigenous innovation activities structurally affect the pace of regional growth in China.

More precisely, differences in both IFDI and KS endowments are expected to participate in setting interregional disparities and, therefore, differentiating the development process on a local basis. The empirical analysis tests this hypothesis in a model of conditional convergence that considers three periods and prefectural cities to address a proper variability within and across groups.

\section{Development drivers and regional disparities in China}

Differences in technological capabilities are major determinants of income gaps across countries. Therefore, latecomers can take the most advantage of IFDI as a source of additional and more recent technologies (Lall 1992). When successfully implemented — as in China — policy actions to attract IFDI are able to boost economic growth and 
foster new capabilities at a local level (Naughton 2007). As a side effect, however, clustering processes can strengthen structural disparities within countries.

The Chinese national government started systematically taking on regional gaps in 1999 with the "Go-West Strategy". Before 2004, this kind of initiative had defined three regions of coordinated development in addition to the Coastal area ( $\mathrm{Li}$ and $\mathrm{Wu}$ 2012). Paces of growth should coherently differ among the regions, and income levels should converge faster within, rather than across, regions. Furthermore, fast growth and structural change continue shaping the development paths, so that geography and history together make the convergence paces local.

\section{Testing convergence to local steady states}

This paper presents an empirical test based on an endogenous growth model. This framework usually considers catching up as conditional on the net accumulation of physical $s_{i t} / d_{i t}$ and human $h_{i}$ capital in addition to the initial income level $y_{i 0}$ (Barro and Sala-I-Martin 2004). There is room, however, for introducing other drivers like IFDI $f_{i t}$ and indigenous KS $k_{i t}$. Moreover, the model lets the convergence parameter vary over time $\tau_{t}$ and regions $\rho_{i}$ as follows:

$$
\ln \left(y_{i t} / y_{i 0}\right)=b_{y \tau \rho}\left(1+\tau_{t} \times \rho_{i}\right) \ln \left(y_{i 0}\right)+b_{s} \ln \left(s_{i t}\right)+b_{d} \ln \left(d_{i t}\right)+b_{h} \ln \left(h_{i t}\right)+b_{f} \ln \left(f_{i t}\right)+b_{k} \ln \left(k_{i t}\right)+u_{i t}(1)
$$

The literature usually considers 31 provinces for which most statistics since the late-70s are available. Nonetheless, such an administrative level is excessively broad to provide proper variability, and the analysis focuses here on prefectures. All data but KS come from China Data On Line (CDOL), which collects yearly statistics for most prefectural cities in China from 1996 onwards. After excluding incomplete records, the dataset consists of 260 individuals among 345 total, grouped in East (87), Midland (81), Northeast (33) and West (59). The analysis also considers time through splitting records 
into three five-year spans from 1996 to 2010 . Therefore, $y_{i 0}$ and $y_{i t}$ are GDP per capita at the first and last year in each period, respectively, while the other explanatory variables enter the model as yearly period averages (Table 1).

[Table 1 near here]

In particular, the amount of domestic and foreign investments in fixed assets over GDP easily function as proxies of saving rate and IFDI respectively. The population growth rate is instead augmented by the obsolescence rate calibrated in Mankiw, Romer, and Weil (1992) to proxy the depreciation rate of physical capital. Then, the enrolment in secondary school approximates human capital as common in growth empirics since Barro and Lee (1994). Here, it is calculated as the number of students enrolled in secondary school over population.

KS finally is a common measure built on patent counts (Popp 2002), but CDOL unfortunately does not collect prefectural patent information. As an alternative, the analysis refers to patent applications from Chinese applicants to the European Patent Office (EPO), which are collected in the OECD, REGPAT Database, January 2014. REGPAT also exclusively attributes patent documents from China to provinces, but the database information is detailed enough to rearrange data at the prefectural level based on applicants' addresses (Callaert et al. 2011). In this regard, the dataset is new to the literature.

Regressions implement an OLS estimation of pooled cross-sectional data, preventing complexities due to serial autocorrelation and individual fixed effects in panel estimation. The analysis rests upon two analogous regression sets. The first consists of usual tests of convergence serving as benchmarks for discussion, and the second addresses group variability. Differences between convergence paces are expected to disappear, at least partially, by adding determinants to the estimation model. 


\section{Results and discussion}

The results from conventional tests of growth convergence (Table 2) provide three basic hints. First, there is no absolute convergence across Chinese prefectures during the observed period (2.1), motivating the authors to then look into growth drivers as proxies for steady-state income levels. Second, all variables exhibit significant coefficients with the expected signs (2.2-2.5). Third, the estimated convergence rates are congruent with those usually presented in literature, although they are slightly higher. This evidence is however supposed to be consistent with fast economic growth.

[Table 2 near here]

Table 3 then reports the results from the second regression set. The coefficient associated with the initial income level $y_{i 0}$ can now vary across groups. The second and third subscript of $y$ denote periods $\tau_{t}$ and regions $\rho_{i}$, respectively: 1996-2000 (1), 20012005 (2) and 2006-2010 (3); East (0), Midland (1), Northeast (2) and West (3).

Accordingly, $y_{i 10}$ concerns Eastern prefectural cities between 1996 and 2000, while the other group-related coefficients are in differences from $b_{10}$.

[Table 3 near here]

When no proxy enters the model but the coefficient associated with the initial income level can vary, growth rates converge within groups (3.1). The estimated differences are indeed significant, confirming that convergence across groups is poor. Furthermore, additional variables still exhibit significant coefficients with the expected signs, and the model explanatory power earns 9 percentage points more with respect to the analogous regressions in Table 2 (3.2-3.5). 
Finally, Table 4 reports the speed of convergence $\lambda$ implied by regressions. The first row of values refers to the overall rates from Table 2, and the following rows refer to the local rates from Table 3. As mentioned, there is no overall possibility for latecomers to catch up with the richest cities without considering growth conditions (4.1 2). Catch up, however, exists if restricted, for instance, to the Eastern prefectures between 1996 and $2010\left(4.1 \lambda_{10}\right)$. In this group, a latecomer would need 18 years to catch up halfway with the frontier. In contrast, the same catch up would occur in 24 years in Midland between 2006 and $2010\left(4.1 \lambda_{31}\right)$. In general, convergence rates also tend to decrease over time (4.1-4.5).

\section{[Table 4 near here]}

Introducing explanatory variables produces two more items of evidence. First, the speed of convergence increases. Fourteen years was indeed enough to halve the gap among Eastern prefectures between 1996 and 2000, considering the effect of IFDI $\left(4.3 \lambda_{10}\right)$. The years needed to catch up further decreases to 11 if the model includes both IFDI and KS $\left(4.5 \lambda_{10}\right)$. Then, they are actual sources of disparity within groups.

Second, significant differences between local convergence rates become less numerous. This also means that convergence across groups depends on the considered proxies. Human capital and KS, however, appear to be more effective than IFDI in capturing disparities, given that some differences are persistently significant when IFDI enters the model $\left(4.3 \lambda_{20}, \lambda_{23}, \lambda_{31}\right.$ and $\lambda_{33} ; 4.5 \lambda_{31}$ and $\left.\lambda_{33}\right)$. This suggests that the impact of these drivers on growth rates is probably uneven and the development path asymmetrical, reinforcing the hypothesis of structural disparities.

\section{Conclusions}

This paper shows that economic growth is structurally unbalanced in China. In doing 
this, it contributes to the literature with new data and methodological approach. More precisely, convergence rates across groups of prefectural cities vary with time and region and are conditional on usual endogenous growth drivers, as well as on IFDI and KS. EPO patents from China work to approximate structural disparities within and across groups, although they are highly selective in measuring the actual endowment of indigenous technological capabilities. This probably stresses the effectiveness of KS in capturing disparities and deserves more investigation. Baseline regression results are, however, satisfactorily congruent with those reported in the literature on growth empirics.

\section{References}

Barro, R. J., and J.-W. Lee. 1994. "Sources of Economic Growth.” Carnegie-Rochester Conference Series on Public Policy 40: 1-46. doi:10.1016/0167-2231(94)90002-7.

Barro, R. J., and X. I. Sala-I-Martin. 2004. Economic Growth. Second. Cambridge MA: MIT Press.

Callaert, J., M. du Plessis, J. Growels, C. Lecocq, T. Magerman, B. Peeters, X. Song, B. Van Looy, and C. Vereyen. 2011. Patent Statistics at Eurostat: Methods for Regionalisation, Sector Allocation and Name Harmonisation. Eurostat. Luxembourg.

Fan, P. 2014. “Innovation in China.” Journal of Economic Surveys 28: 725-745. doi:10.1111/joes.12083.

Fu, X. 2008. "Foreign Direct Investment, Absorptive Capacity and Regional Innovation Capabilities: Evidence from China.” Oxford Development Studies 36: 89-110. doi:10.1080/13600810701848193.

Lall, S. 1992. “Technological Capabilities and Industrialization.” World Development 20: 165-186. doi:10.1016/0305-750X(92)90097-F. 
Li, X., and X. Liu. 2005. "Foreign Direct Investment and Economic Growth: An Increasingly Endogenous Relationship.” World Development 33: 393-407. doi:10.1016/j.worlddev.2004.11.001.

Li, Y., and F. Wu. 2012. "The Transformation of Regional Governance in China: The Rescaling of Statehood.” Progress in Planning 78: 55-99. doi:10.1016/j.progress.2012.03.001.

Mankiw, N. G., D. Romer, and D. N. Weil. 1992. “A Contribution to the Empirics of Economic Growth.” The Quarterly Journal of Economics 107: 407-437. doi:10.2307/2118477.

Naughton, B. 2007. The Chinese Economy: Transitions and Growth. Cambridge MA: MIT Press.

Popp, D. 2002. "Induced Innovation and Energy Prices.” American Economic Review 92: 160-180. doi:10.1257/000282802760015658. 
Table 1. Description of variables and summary statistics $(\mathrm{N}=780)$.

\begin{tabular}{|c|c|c|c|c|c|}
\hline & Description & $\mu$ & $\sigma$ & $\min$ & $\max$ \\
\hline$y_{i t}$ & GPD per capita at 2009 prices, $\log$ & 9.571 & 0.869 & 6.611 & 12.815 \\
\hline$y_{i 0}$ & Initial level of GPD per capita at 2009 prices, $\log$ & 9.134 & 0.778 & 6.654 & 12.658 \\
\hline$s_{i}$ & Investment in fixed assets over GDP, 5-year average, log & -1.115 & 0.522 & -2.722 & 0.111 \\
\hline$d_{i}$ & $\begin{array}{l}\text { Depreciation rate: population growth rate }+0.05 \text {, } \\
5 \text {-year average, } \log \end{array}$ & -2.892 & 0.056 & -3.031 & -2.559 \\
\hline$h_{i}$ & $\begin{array}{l}\text { Secondary school enrolment: number of students over } \\
\text { population, 5-year average, log }\end{array}$ & -2.833 & 0.260 & -4.472 & -2.047 \\
\hline$f_{i}$ & $\begin{array}{l}\text { Inward Foreign Direct Investments over GDP, 5-year } \\
\text { average, log }\end{array}$ & -4.399 & 1.286 & -9.438 & -0.610 \\
\hline$k_{i}$ & $\begin{array}{l}\text { Knowledge stock per million inhabitants, 5-year } \\
\text { average, log }\end{array}$ & 0.163 & 0.473 & 0 & 6.476 \\
\hline
\end{tabular}


Table 2. Results from the first regression set $(\mathrm{N}=780)$.

\begin{tabular}{lccccc}
\hline & $(2.1)$ & $(2.2)$ & $(2.3)$ & $(2.4)$ & $(2.5)$ \\
\hline$y_{i 0}$ & 0.005 & $-0.118^{* * *}$ & $-0.139^{* * *}$ & $-0.155^{* * *}$ & $-0.174^{* * *}$ \\
$s_{i t}$ & $0.304^{* * *}$ & $0.312^{* * *}$ & $0.313^{* * *}$ & $0.319^{* * *}$ \\
$d_{i t}$ & $-1.106^{* * *}$ & $-1.132^{* * *}$ & $-1.119^{* * *}$ & $-1.144^{* * *}$ \\
$h_{i t}$ & $0.405^{* * *}$ & $0.396^{* * *}$ & $0.400^{* * *}$ & $0.391^{* * *}$ \\
$f_{i t}$ & & $0.028^{* *}$ & & $0.026^{* *}$ \\
$k_{i t}$ & & & $0.094^{* *}$ & $0.091^{* *}$ \\
\hline$R^{2}$ & & 0.247 & 0.249 & 0.255 \\
\hline \multicolumn{2}{c}{ OLS estimator; robust standard errors } \\
${ }^{*} \mathrm{p}<0.1,{ }^{* *} \mathrm{p}<0.05,{ }^{* * *} \mathrm{p}<0.01$ & & &
\end{tabular}


Table 3. Results from the second regression set $(\mathrm{N}=780)$.

\begin{tabular}{|c|c|c|c|c|c|}
\hline & $(3.1)$ & $(3.2)$ & $(3.3)$ & $(3.4)$ & $(3.5)$ \\
\hline$y_{i 10}$ & $-0.142^{* * *}$ & $-0.161^{* * *}$ & $-0.182^{* * *}$ & $-0.205^{* * *}$ & $-0.222^{* * *}$ \\
\hline$y_{i 11}-y_{i 10}$ & $-0.036^{* * *}$ & $-0.034^{* * *}$ & $-0.032^{* * *}$ & $-0.036^{* * *}$ & $-0.033^{* * *}$ \\
\hline$y_{i 12}-y_{i 10}$ & $-0.010^{*}$ & $-0.011^{*}$ & -0.008 & $-0.012^{* *}$ & -0.009 \\
\hline$y_{i 13}-y_{i 10}$ & $-0.052^{* * *}$ & $-0.044^{* * *}$ & $-0.040^{* * *}$ & $-0.046^{* * *}$ & $-0.042^{* * *}$ \\
\hline$y_{i 20}-y_{i 10}$ & $0.025^{* * *}$ & 0.009 & $0.011^{*}$ & 0.008 & $0.010^{*}$ \\
\hline$y_{i 21}-y_{i 10}$ & 0.009 & -0.007 & -0.003 & -0.007 & -0.004 \\
\hline$y_{i 22}-y_{i 10}$ & $0.011^{* *}$ & -0.001 & 0.004 & -0.001 & 0.004 \\
\hline$y_{i 23}-y_{i 10}$ & $0.022^{* * *}$ & 0.006 & $0.011^{*}$ & 0.004 & 0.008 \\
\hline$y_{i 30}-y_{i 10}$ & $0.023^{* * *}$ & 0.007 & $0.011^{*}$ & 0.003 & 0.007 \\
\hline$y_{i 31}-y_{i 10}$ & $0.029^{* * *}$ & 0.011 & $0.015^{* *}$ & 0.011 & $0.014^{*}$ \\
\hline$y_{i 32}-y_{i 10}$ & $0.034^{* * *}$ & $0.017^{* * *}$ & $0.022^{* * *}$ & $0.018^{* * *}$ & $0.022^{* * *}$ \\
\hline$y_{i 33}-y_{i 10}$ & $0.028^{* * *}$ & 0.009 & $0.017^{* *}$ & 0.009 & $0.016^{* *}$ \\
\hline$s_{i t}$ & & $0.163^{* * *}$ & $0.151^{* * *}$ & $0.173^{* * *}$ & $0.163^{* * *}$ \\
\hline$d_{i t}$ & & $-0.854^{* * *}$ & $-0.878^{* * *}$ & $-0.860^{* * *}$ & $-0.880^{* * *}$ \\
\hline$h_{i t}$ & & $0.268^{* *}$ & $0.268^{* *}$ & $0.261^{* *}$ & $0.260^{* *}$ \\
\hline$f_{i t}$ & & & $0.025^{* *}$ & & $0.022^{*}$ \\
\hline$k_{i t}$ & & & & $0.122^{* * *}$ & $0.118^{* * *}$ \\
\hline$R^{2}$ & 0.284 & 0.332 & 0.336 & 0.345 & 0.348 \\
\hline
\end{tabular}

OLS estimator; robust standard errors ${ }^{*} \mathrm{p}<0.1,{ }^{* *} \mathrm{p}<0.05,{ }^{* * *} \mathrm{p}<0.01$ 
Table 4. Implied speed of converge $\lambda$.

\begin{tabular}{cccccc}
\hline & $(4.1)$ & $(4.2)$ & $(4.3)$ & $(4.4)$ & $(4.5)$ \\
\hline$\lambda$ & -0.001 & $0.031^{* * *}$ & $0.037^{* * *}$ & $0.042^{* * *}$ & $0.047^{* * *}$ \\
\hline$\lambda_{10}$ & $0.038^{* * *}$ & $0.043^{* * *}$ & $0.050^{* * *}$ & $0.057^{* * *}$ & $0.062^{* * *}$ \\
$\lambda_{11}$ & $0.048^{* * *}$ & $0.054^{* * *}$ & $0.060^{* * *}$ & $0.068^{* * *}$ & $0.073^{* * *}$ \\
$\lambda_{12}$ & $0.041^{*}$ & $0.047^{*}$ & 0.052 & $0.061^{*}$ & 0.065 \\
$\lambda_{13}$ & $0.053^{* * *}$ & $0.057^{* * *}$ & $0.062^{* * *}$ & $0.072^{* * *}$ & $0.076^{* * *}$ \\
$\lambda_{20}$ & $0.031^{* * *}$ & 0.041 & $0.046^{*}$ & 0.054 & 0.059 \\
$\lambda_{21}$ & $0.035^{*}$ & 0.045 & 0.051 & 0.059 & 0.064 \\
$\lambda_{22}$ & $0.035^{* *}$ & 0.044 & 0.049 & 0.057 & 0.061 \\
$\lambda_{23}$ & $0.031^{* * *}$ & 0.042 & $0.046^{*}$ & 0.056 & 0.060 \\
$\lambda_{30}$ & $0.031^{* * *}$ & 0.041 & $0.046^{*}$ & 0.056 & 0.060 \\
$\lambda_{31}$ & $0.029^{* * *}$ & 0.040 & $0.045^{*}$ & 0.054 & $0.058^{*}$ \\
$\lambda_{32}$ & $0.028^{* * *}$ & $0.038^{* * *}$ & $0.043^{* * *}$ & $0.051^{* * *}$ & $0.055^{* * *}$ \\
$\lambda_{33}$ & $0.030^{* * *}$ & 0.041 & $0.045^{* *}$ & 0.054 & $0.057^{* *}$ \\
\hline
\end{tabular}

$\lambda$ and $\lambda_{10}{ }^{*}$ refers to the significance level of the estimated coefficients

$\lambda_{\tau \rho}:{ }^{*}$ refers to the significance level of differences from $\lambda_{10}$

${ }^{*} \mathrm{p}<0.1,{ }^{* *} \mathrm{p}<0.05,{ }^{* * *} \mathrm{p}<0.01$ 